Grand Valley State University

ScholarWorks@GVSU

8-2005

\title{
Attitudes Mediate the Association Between Childhood Disciplinary History and Disciplinary Responses
}

Mary Bower-Russa

Grand Valley State University, bowerm@gvsu.edu

Follow this and additional works at: https://scholarworks.gvsu.edu/psy_articles

Part of the Psychology Commons

\section{ScholarWorks Citation}

Bower-Russa, Mary, "Attitudes Mediate the Association Between Childhood Disciplinary History and Disciplinary Responses" (2005). Peer Reviewed Articles. 51.

https://scholarworks.gvsu.edu/psy_articles/51

This Article is brought to you for free and open access by the Psychology Department at ScholarWorks@GVSU. It has been accepted for inclusion in Peer Reviewed Articles by an authorized administrator of ScholarWorks@GVSU.

For more information, please contact scholarworks@gvsu.edu. 


\title{
Attitudes Mediate the Association Between Childhood Disciplinary History and Disciplinary Responses
}

\author{
Mary Bower-Russa \\ Grand Valley State University
}

\begin{abstract}
According to recent estimates, childhood abuse victims are at 12 times higher risk for child abuse perpetration than those without such abusive histories. This study focused on delineation of the mechanisms by which intergenerational patterns of abuse may occur and, in particular, the role that disciplinary attitudes may play in mediating the relation between disciplinary history and risk for abusive parenting. Participants $(\mathrm{n}=459)$ completed a series of questionnaires to assess childhood history, disciplinary attitudes, and disciplinary practices. Structural equation modeling indicated that the association between disciplinary history and disciplinary responses was partially mediated by attitudes, with more than half of the association between history and responses accounted for by attitudes. These findings support the need for interventions to focus on attitudinal change when attempting to reduce risk for perpetration among those with histories of abuse.
\end{abstract}

Keywords: child abuse; transgenerational patterns; disciplinary attitudes; physical discipline; escalation

$\mathbf{I}_{1}$ complex dynamics that lead to childhood physical abuse, one risk factor that has drawn considerable attention in the literature historically is a history of childhood physical maltreatment (e.g., Bower-Russa, Knutson \& Winebarger, 2001; Gelles, 1973; Kaufman \& Zigler, 1989; Rutter, 1983; Steele \& Pollack, 1974; Widom, 1989). In a recent review of this literature,

CHILD MALTREATMENT, Vol. 10, No. 3, August 2005 272-282 DOI: $10.1177 / 1077559505277531$

(C) 2005 Sage Publications
Ertem, Leventhal, and Dobbs (2000) noted a range of methodological shortcomings in the existing research in this area. In fact, their methodological critique identified only 1 of the 10 studies (i.e., Egeland, Jacobvitz, \& Sroufe, 1988) that they reviewed that showed an appropriate level of methodological rigor. Notably, however, using data from that study, the risk for mothers who were abused during childhood to abuse their children was 12 times higher than the risk for mothers with supportive parents during childhood (Ertem et al., 2000). Thus, although the majority of childhood abuse victims do not become abusers, a history of childhood maltreatment must be considered an important risk factor for later abuse perpetration. The purpose of the present study was to more clearly delineate the mechanisms by which childhood history of abuse can be associated with increased risk for punitive parenting and, specifically, to clarify the role that attitudes may play in accounting for this association.

A significant literature has focused on parental attitudes and the role that they may play in parental disciplinary responding. For example, attitudes that are devaluing of children have been associated with parental use of physical discipline in the home (e.g.,

\footnotetext{
Author's Note: Requests for reprints and correspondence regarding this article should be addressed to: Mary Bower-Russa, Department of Psychology, Grand Valley State University, One Campus Drive, 2138 ASH, Allendale, Michigan 49401; phone 616-331-2907; e-mail: bowerm@gvsu.edu.
}

The author acknowledges Bill Rogers for his consultation regarding statistical analyses. John Knutson reviewed and provided helpful feedback on this manuscript, and Allen Winebarger assisted with data collection. 
Jackson et al., 1999; Thompson, Christiansen, Jackson, \& Wyatt, 1999). Additionally, abusive mothers have been found to have more negative perceptions of the abused child (Larrance \& Twentyman, 1983), more unrealistic expectations regarding attainment of developmental milestones, and difficulties in problem-solving to manage child behaviors (Azar, Robinson, Hekimian, \& Twentyman, 1984; Williamson, Borduin, \& Howe, 1991). Perception of the child being deserving of harsh discipline has also been identified as an important attitudinal factor in predicting parental responding because when a child is considered to be misbehaving, they are more likely to be blamed for disciplinary outcomes (e.g., Kelder, McNamara, Carlson, \& Lynn, 1991; Rodriguez \& Price, 2004). In fact, children who view their disciplinary treatment as deserved are more likely to justify their own abusive experiences (Rausch \& Knutson, 1991) and are at increased risk for later abusive parenting (Rodriguez \& Price, 2004). When attitudes regarding general disciplinary approaches are considered, belief in authoritarian control strategies (Susman, Trickett, Iannotti, Hollenbeck, ZahnWaxler, 1985) and the value of corporal punishment (Crouch \& Behl, 2001) have both been linked to increased child abuse potential.

Research suggests that the attitudes that are most likely to be linked with future behavior are the attitudes specific to that particular behavior (e.g., Kraus, 1995); hence, disciplinary attitudes have been a significant focus of the research on parental disciplinary responding. Several decades of research on disciplinary attitudes in the general population indicate high rates of acceptance and approval of violence in parenting contexts. In the first national violence survey, $70 \%$ to $77 \%$ of those surveyed indicated that slapping or spanking a 12-year-old child was at least somewhat normal, necessary, and good (Straus, Gelles, \& Steinmetz, 1980). In a more recent survey of 450 parents making pediatric visits, approval rates for even the more violent forms of discipline were surprisingly high: $88 \%$ approved of spanking, $17 \%$ approved of shaking, and 6\% approved of burning (BuntainRicklefs, Kemper, Bell, \& Babonis, 1994). Research with college students suggests that the belief that physical violence constitutes appropriate discipline exists even prior to parenthood. In Graziano and Namaste's (1990) survey of 700 college freshmen, $85 \%$ believed that parents had the right to spank and $83 \%$ indicated that they intended to spank their own children. Importantly, personal family experiences appear to play a significant role in the attitudes that individuals develop toward physical disciplinary strategies. Thus, those who have experienced a particular type of punishment (e.g., shaking, spanking, hitting with an object) view that form of discipline as less severe and more appropriate, are more likely to approve of it, and are less likely to label the discipline abusive (Bower \& Knutson, 1996; Bower-Russa et al., 2001; Buntain-Ricklefs et al., 1994; Herzeberger \& Tennen, 1985).

Much of the recent attitudinal research has focused on the exploration of a social-cognitive model, whereby transgenerational patterns of abuse may reflect a tendency for the experience of punitive punishment to influence the beliefs that those punitively punished children develop regarding the appropriateness and effectiveness of various types of disciplinary strategies (e.g., Bower-Russa et al., 2001; Crouch \& Behl, 2001; Deater-Deckard, Pettit, Lansford, Dodge, Bates, 2003). Thus, the tendency to be more accepting of physical discipline in general, and punitive disciplinary strategies specifically, may increase these children's risk for abuse perpetration when they become parents.

The determinants of parental disciplinary behavior are surely very complex; however, disciplinary attitudes have long been hypothesized to play a significant role in accounting for the tendency for persons who experience abuse to be at increased risk to abuse their own children (e.g., Herzeberger, 1983; Kelder et al., 1991). Consistent with such a notion, belief in spanking correlates significantly with both practice (0.46) and severity (0.36) of spanking for parents of children under the age of 4 (Socolar \& Stein, 1995). With regard to punitive discipline, Straus (1992) has reported that parents believing in the use of physical punishment hit their children more often, use extreme forms of punishment more often, and have an abuse rate that is four times higher than that of those who do not approve of physical punishment.

Whether such beliefs do, in fact, mediate transgenerational patterns of abuse is less clear, although several researchers have presented data that are consistent with this possibility. In the Bower-Russa et al. (2001) attempt to identify factors that could contribute to intergenerational patterns of abuse, college students' attitudes regarding disciplinary practices were influenced by disciplinary history, and both history and attitudes were significant predictors of disciplinary responses in a parenting analogue task. These associations are not unique to college students or to analogue designs. Using a sample of parents in New Zealand, Rodriguez and Sutherland (1999) demonstrated that childhood history of discipline was associated with judgments of the severity of disciplinary techniques, and that parents' history and severity judgments were associated with the frequency of use 
of such strategies with their own children. Taken together, these findings are consistent with the possibility that attitudes mediate transgenerational patterns of abuse; however, neither Bower-Russa et al. (2001) nor Rodriguez and Sutherland (1999) explored the role that disciplinary attitudes play as mediators per se.

Mediation (which is distinct from, but often confused with, moderation or with an indirect effect) addresses the mechanism by which the independent variable influences the dependent variable (see Baron \& Kenny, 1986; Holmbeck, 1997). As such, increased understanding of patterns of mediation can have important implications for prevention and intervention programming (MacKinnon \& Dwyer, 1993). The present study focused on exploration of whether, and to what extent, disciplinary attitudes mediate the association between disciplinary history and disciplinary responding.

A significant complicating factor in attempts to understand the role that attitudes play in the risk for initial abusive parenting is that once a parent uses punitive discipline, they may be inclined to modify their attitudes to justify their behaviors (Jackson et al., 1999); hence, the initial role that attitudes play may be obscured by the ongoing interplay between attitudes and behaviors. Given that student and other preparent populations show high degrees of concordance with parent populations in their attitudes regarding disciplinary acts (Bower \& Knutson, 1996; Portwood, 1998) but have not yet had to function in a parenting role, such preparent groups offer an important opportunity for the investigation of the original patterns of association between disciplinary history, attitudes, and behaviors (e.g., Rodriguez \& Price, 2004). The present study focused on use of such a preparent population to examine the impact of a mediator that could potentially be targeted in the increasing push for primary prevention efforts focused on preparent and new parent populations (e.g., Bavolek, 1989; Flynn, 1998; Margolin \& Craft, 1990; Masten, Best, \& Garmezy, 1990; Zoline \& Jason, 1985).

\section{METHOD}

\section{Participants}

The participants in the study were 459 undergraduate students (i.e., future parents; Bogaard, 1976) at a Midwestern university. Students were involved in this study as one of several options to meet a research participation requirement for their introductory psychology course. Because introductory psychology is a course that satisfies general education requirements, most students at the university enroll in the course. The data were collected during two consecutive semesters. The final sample was comprised primarily of participants between the ages of 18 and 20 (91\%) who were in their 2nd or 3rd year of university studies $(83 \%)$ and were unmarried (98\%) with no children of their own $(97 \%)$. Participants were almost exclusively Caucasian (92\%), with small representations of those who identified themselves as Asian American $(1 \%)$, African American (5\%), Hispanic (.5\%), or Other $(1.5 \%)$. Most participants grew up in areas with a population of less than $100,000(78 \%)$, with only $8 \%$ from large urban areas of more than 510,000 . The majority of the sample identified their family economic group as middle (82\%), although $9 \%$ identified their economic group as high, and $6 \%$ as low. Although the sample was broadly representative of the student population at the university with regard to other demographic variables, there was an overrepresentation of women in the sample $(75 \%)$ when compared to the demographics at the university $(60 \%)$.

\section{Measures}

Participants completed measures in each of the following areas: disciplinary history, disciplinary attitudes, parenting responses.

Disciplinary history. Disciplinary history was assessed using two measures: the Physical Punishment Scale of the Assessing Environments III Questionnaire (AEIII), and the Similarity Scale of the Perceptions Of Parenting (POPA).

The 130-item AE-III is a true-false questionnaire that has been used to obtain information regarding childhood histories of college students (e.g., Berger, Knutson, Mehm, \& Perkins, 1988; Bower-Russa et al., 2001) as well as sexual offenders (Worling, 1995), psychiatric patients (Whitmore, Kramer \& Knutson, 1993), patients with posttraumatic stress disorder (Zaidi \& Foy, 1994), and incarcerated felons (Miller \& Knutson, 1997). The questionnaire includes a variety of scales designed to assess characteristics of families that have been associated with abuse (Knutson \& Mehm, 1988) as well as the experience of events assessed as abusive in the general literature (e.g., Gil, 1970; Sapp \& Carter, 1978; Straus, 1980). The scales of the AE-III have demonstrated adequate test-retest reliability and interitem consistency in prior research (Berger et al., 1988). The scale of interest in this study, the Physical Punishment Scale, asks about childhood experiences ranging from mild forms of physical pun- 
ishment (e.g., spanking) to more punitive forms of physical discipline (e.g., striking with objects, choking). Events that were endorsed were summed to yield a Physical Punishment Scale score, which reflected severity of physical punishment history. In past research, scores on the Physical Punishment Scale have been found to distinguish between abused and nonabused adolescents (Berger et al., 1988) and to correlate significantly with aversive events recorded during direct home observations conducted approximately 10 years earlier (Prescott et al., 2000).

The POPA Similarity Scale questionnaire (Winebarger, Leve, Fagot \& May, 1993) comprised a second measure of disciplinary history. The original POPA questionnaire asked respondents to evaluate the harshness, appropriateness, and effectiveness of 61 descriptions of parental behaviors ranging from praising a child, to calling a child stupid or hitting a child with objects. The Similarity Scale was added as part of the revised POPA questionnaire (Bower-Russa et al., 2001). This scale asks respondents to indicate how similar the described parent behavior is to their own childhood experiences. Average similarity scores were calculated based on responses to the nine items of the questionnaire that focused on physical forms of discipline $(\alpha=.818)$. The original questionnaire and the modification of it have been used in past research focused on disciplinary attitudes and parenting (e.g., Bower-Russa et al., 2001; Winebarger et al., 1993) .

Disciplinary attitudes. Disciplinary attitudes were assessed using two measures: ratings of disciplinary events from the original scales of the POPA questionnaire and the Abuse Opinion Survey-Revised. For the first measure, to create a composite attitudinal score using responses to the POPA questionnaire (described above), harshness and appropriateness scores (the latter reversed for scoring) were averaged across physical punishment items to create a disciplinary attitudes score (POPA Attitudes). On this composite scale $(\alpha=.885)$, higher scores were indicative of ratings of parental physical discipline as more harsh and less appropriate.

A second measure of disciplinary attitudes, the Abuse Opinion Survey, has been used in prior research focusing on disciplinary attitudes (Bower \& Knutson, 1996; Bower-Russa et al., 2001). This questionnaire includes descriptions of a broad range of parental behaviors and asks respondents to categorize them as no abuse or as a specific type of abuse (physical, emotional, sexual). In the revised version (Bower-Russa et al., 2001), used in the present study, the respondent is also asked how abusive (on a 0 to 7 Likert scale) they find each behavior. These abuse rat- ings for items involving physical discipline were averaged to yield overall scores in which higher scores reflected ratings of events as more abusive $(\alpha=.816)$.

Parenting responses. Disciplinary responding was assessed using the analog parenting task. The analog parenting task has proven to be a useful measure in prior research focused on risk for abusive parenting and has repeatedly produced results that are consistent with existing theory regarding transgenerational patterns of abuse (e.g., Bower-Russa et al., 2001; Knutson \& Bower, 1994; Zaidi, Knutson, \& Mehm, 1989). Most recently, this measure has been used to examine risk for physical abuse among parents of children with disabilities (e.g., Knutson, Johnson, \& Sullivan, 2004). In this task, participants view 28 slides depicting children engaging in a range of activities and select a disciplinary strategy that they would use to manage the child's behavior. Child behaviors include a range of dangerous (e.g., sitting on a roof), destructive (e.g., tearing pages out of a book), socially inappropriate (e.g., drinking beer), and control (e.g., playing with tinker toys) acts. Respondents indicate what their initial reaction will be, how many times they would allow the child to persist in that behavior before they would change their response and, if they would change their response, what their next response would be. This measure yields two scores: a physical discipline score (reflecting the frequency with which physical disciplinary responses are selected either initially or if the child persists in the behavior) and an escalation score (reflecting the frequency with which the respondent changes from a nonphysical to physical disciplinary response if the child is described as persisting in the behavior after initial intervention attempts). Use of the analogue parenting task as a measure of risk for abuse is consistent with the fact that abusive parenting events most often occur in the context of a disciplinary exchange between parent and child (Gil, 1970; Herrenkohl, Herrenkohl, \& Egolf, 1983), and escalation from acceptable to punitive responding in the face of child noncompliance appears to play a critical role in abuse perpetration (e.g., Azar \& Wolfe, 1998; Bower \& Knutson, 1996; Reid, 1985; Wahler, Williams \& Cerezo, 1990; Wilson \& Whipple, 1995).

Procedure. Groups of 8 to 12 participants attended a 2-hour data collection session in which they spent approximately 1 hour completing paper-and-pencil questionnaires (i.e., AE-III, Abuse Opinion Survey-R, POPA) and another hour responding to a slide presentation (analog parenting task). Questionnaires and slide portions were administered in counterbalanced order, but preliminary analyses indicated no 
TABLE 1: Correlations Among Variables Measured

\begin{tabular}{|c|c|c|c|c|c|}
\hline Variable & 1 & 2 & 3 & 4 & 5 \\
\hline \multicolumn{6}{|l|}{ 1. Physical Punishment Scale } \\
\hline 2. Perceptions of Parenting Similarity Scale & $.689 * *$ & & & & \\
\hline 3. Abuse Opinion Survey & $-.314 * *$ & $-.348 * *$ & & & \\
\hline 4. Perceptions of Parenting Attitudes & $-.374 * *$ & $-.463 * *$ & $.628^{* *}$ & & \\
\hline 5. Physical Discipline on Analog Parenting Task & $.297 * *$ & $.280 * *$ & $-.286 * *$ & $-.366^{* *}$ & \\
\hline 6. Escalation on Analog Parenting Task & $.289 * *$ & $.235^{* *}$ & $-.269 * *$ & $-.327 * *$ & $.867 * *$ \\
\hline
\end{tabular}

$* p<.05 . * * p<.01$.

order effects, so results reflect data collapsed across counterbalanced conditions.

The study, which was approved by the Institutional Review Board, followed the procedure of BowerRussa et al. (2001). Briefly, to encourage candid responding, participants were assigned idiosyncratic identification numbers on admission to the test session. After signing in and completing informed consent forms, participants were instructed to place this idiosyncratic number on each of their answer materials. Hence, these numbers allowed anonymity in responding while providing for identification and matching of response materials for later analyses. Respondents were repeatedly reminded not to put any personally identifying information on answer sheets, and as each questionnaire was completed, the participant placed it in a privacy envelope.

\section{Overview of Analyses}

Structural equation modeling (SEM; Arbuckle \& Wothke, 1999) was used to assess the fit of a preliminary model in which attitudes fully mediated the relation between childhood disciplinary history and adult disciplinary responses. In examining relations among constructs of interest, SEM has several important advantages compared to other statistical approaches: It can increase the accuracy of the estimation of the correlation between constructs (Newcomb, 1990, p. 42 ), and it can be used to test the overall fit of a model to the data. Analyses followed procedures for testing for mediation as specified by Baron and Kenny (1986) and elaborated by Holmbeck (1997). These authors note that several steps are required to test for mediation: (a) The predictor must be associated with the dependent variable; (b) the predictor must be associated with the mediator; (c) the mediator must be associated with the dependent variable; and (d) the impact of the predictor on the dependent variable must be reduced by controlling for the mediator.

In testing the mediational model in the present study, the measurement model consisted of three latent variables of interest (i.e., disciplinary history, disciplinary attitudes, and parenting responses), each identi- fied by two observed variables. Following standard procedure, for each of the latent variables, one observed-latent variable path was set to 1.0 to establish scaling. Missing data were handled using maximum likelihood estimation (Arbuckle, 1996). Table 1 presents simple product-moment correlations among the observed variables. Maximum likelihood estimation was used to estimate model parameters, which are presented in standardized form. Preliminary analyses indicated that the model fit the data adequately $\left(\chi^{2}(6)=10.529, p=.104\right)$, and each of the observed variables loaded significantly onto their respective latent variables. (Note that with SEM nonsignificant $p$ values indicate better fit).

\section{RESULTS}

\section{Analyses}

To test for mediation, there must be a statistically significant correlation between the proposed predictor and the dependent variable (see Holmbeck, 1997). As expected, analyses indicated a statistically significant correlation between childhood history and disciplinary responses $(r=.366, p<.05)$ such that more punitive histories were associated with higher rates of potentially injurious parenting responses. Hence, it was appropriate to proceed with the testing of the proposed model in which attitudes served as a mediator of the relation between childhood history and disciplinary attitudes. In this fully mediated model (Figure 1), both the history to attitudes and attitudes to parenting response paths were statistically significant. However, the overall fit of this model to the data was not particularly good $\left(\chi^{2}(7)=16.03, p=.025\right.$; root mean square error of approximation (RMSEA) = .053; comparative fit index $(\mathrm{CFI})=.998)$. To better fit the data, the initial, fully mediated model was revised to a partially mediated model with the addition of a direct path between punishment history and parenting responses (Figure 2). This added path yielded a statistically significant improvement in fit (change $\chi^{2}(1)=5.51, p=.025$ ) and resulted in a revised 


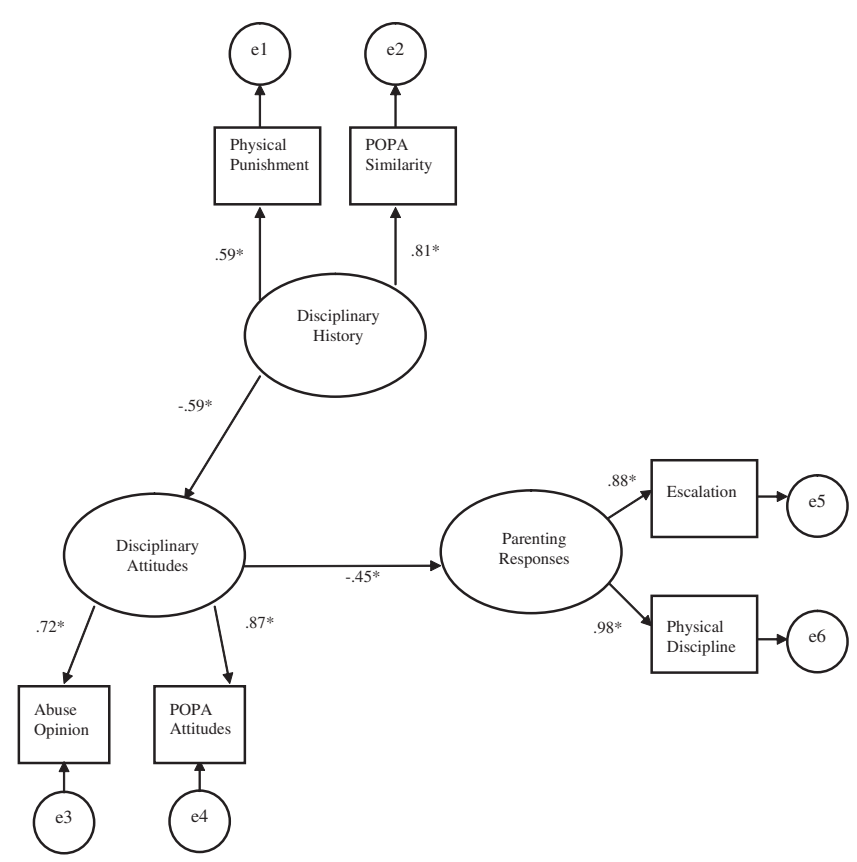

FIGURE 1: $\quad$ The Fully Mediated Model. $\chi^{2}(7)=16.025, p=.025$.

$* p<.05$.

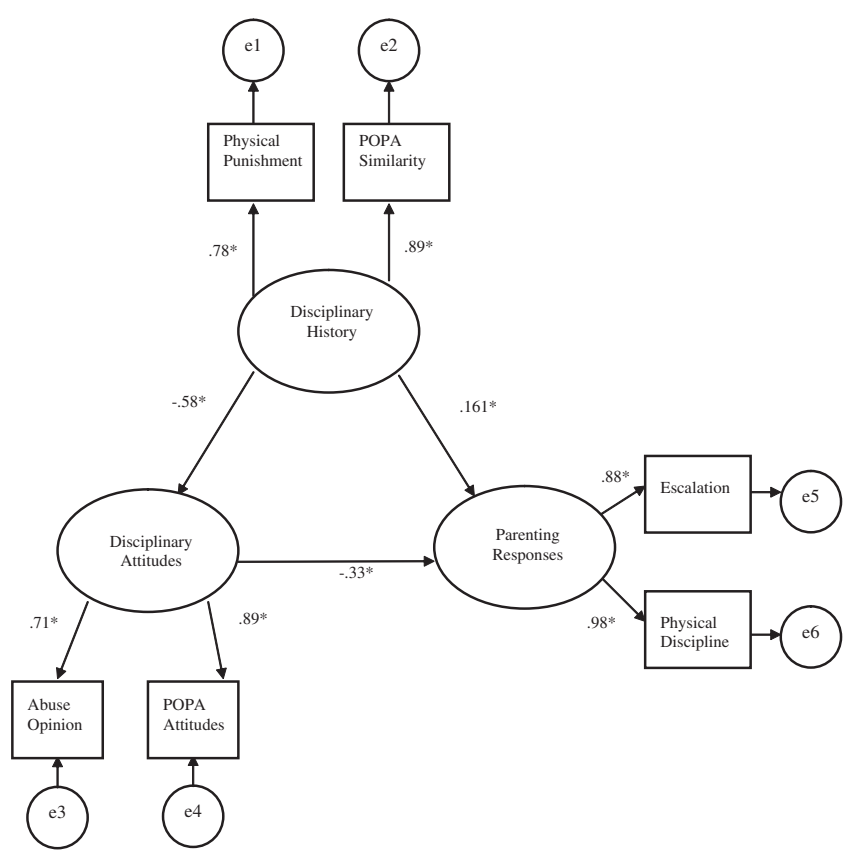

FIGURE 2: $\quad$ The Partially Mediated Model. $\chi^{2}(6)=10.53, p=.104$. $* p<.05$.

model that provided a better overall fit for the data $\left(\chi^{2}(6)=10.53, p=.104 ;\right.$ RMSEA $=.041 ;$ CFI $\left.=.999\right)$.

The association between disciplinary history and parenting responses was significantly reduced with the addition of attitudes as a mediator, from an initial value of .366 in the fully mediated model, to a final value of .161 in the partially mediated model (see Figure 2). This reduction in the association between the predictor and the dependent variable when the mediator was added to the model satisfied the final step in 
testing for mediation (see Holmbeck, 1997), clearly indicating that some of the association between disciplinary history and parenting responses flowed via attitudes. These data support a partially mediated model in which more than half $([.366-.161] / .366=$ $56 \%$ ) of the impact of punishment history on a punitive parenting style is accounted for by the mediation of disciplinary attitudes. An alternate, nonmediated model, in which punishment history was independently associated with disciplinary attitudes and disciplinary responses via two separate pathways was not supported $\left(\chi^{2}(7)=34.31, p=.000 ;\right.$ RMSEA $=.092$; $\mathrm{CFI}=.995)$.

In the final, partially mediated model (Figure 2), the regression weight from disciplinary history to disciplinary attitudes was statistically significant and negative, indicating that the more physical punishment respondents had experienced, the less critical (i.e., more accepting) they were of potentially injurious physical disciplinary strategies. In fact, disciplinary history accounted for approximately $33 \%$ of the variance in attitudes. Disciplinary attitudes, in turn, were significantly negatively associated with parenting responses such that being less critical (more accepting) of potentially injurious physical disciplinary strategies was associated with an increased tendency to select such discipline in responding to child behavior. The additional path from disciplinary history to parenting responses indicated that some of the tendency for more punitive histories to be associated with more severe physical disciplinary responses was not because of the mediation of disciplinary attitudes. This final model accounted for approximately $20 \%$ of the variance in disciplinary choices.

\section{DISCUSSION}

Disciplinary attitudes have been assessed in a variety of ways in the parenting literature. Studies of societal attitudinal patterns have typically focused on the percentage of the public approving of various behavioral acts (e.g., Buntain-Ricklefs et al., 1994; Daro \& Gelles, 1992) as indicated by their ratings of those acts as more acceptable, or less likely to cause harm. Other research (e.g., Graziano \& Namaste, 1990; Jackson et al., 1999; Simons, Whitbeck, Conger, \& Chyi-In, 1991) has assessed to what extent parents subscribe to statements reflecting general philosophical support for physical punishment strategies (e.g., "There is oftentimes no substitute for a good spanking"). However, the majority of the attitudinal literature attempting to predict parental responses has focused on the classification of specific disciplinary behaviors as $a b u$ sive or nonabusive (Bower \& Knutson, 1996) or more continuous ratings of severity, effectiveness, approval, or appropriateness of specific behaviors (Ashton, 2001; Bower-Russa et al., 2001; Herzberger \& Tennen, 1985; Rodriguez \& Sutherland, 1999; Thompson et al., 1999). Because attitudes regarding physical disciplinary acts are likely to be most predictive of future physical disciplinary responses (see Kraus, 1995), the present study used the latter approach, focusing on respondents' ratings of the appropriateness, harshness, and abusiveness of specific disciplinary behaviors.

It should be noted that in examining disciplinary attitudes and responses, this research focused on a full range of physical disciplinary practices (e.g., spanking, hitting, striking with objects) that can be considered potentially injurious but that are not necessarily abusive per se. This approach to the study of risk for child abuse reflects a growing realization that family violence falls along a continuum of acceptability rather than following a clearly delineated dichotomy of abusive and nonabusive. (Simons, Whitbeck, Conger, \& Chyi-In, 1991; Gracia, 1995; Graziano, 1994).

The present study provides preliminary support for the notion that disciplinary attitudes play an important role in intergenerational patterns of abuse. Using a methodological and statistical approach that allowed for correction of measurement error for each of the latent variables of interest (i.e., childhood history of abuse, disciplinary attitudes, and parenting responses), childhood history of punitive discipline was significantly related to increased acceptance of potentially injurious physical disciplinary strategies, accounting for more than a third of the variance in disciplinary attitudes. Thus, family history appears to play a critical role in shaping such disciplinary beliefs.

These findings are consistent with previous research in which children reared in abusive homes view physically violent disciplinary acts as more normal and acceptable than those who do not have such punitive histories (e.g., Bower-Russa et al., 2001; Herzeberger \& Tennen, 1985; Kelder et al., 1991) and with findings that persons who were more approving or more accepting of physical disciplinary practices tend to, in turn, be more likely to use such potentially problematic physical disciplinary practices when faced with child misbehavior (Bower-Russa et al., 2001). Additionally, however, this study provides an indication that disciplinary attitudes may serve as a critical pathway by which a punitive disciplinary history influences disciplinary strategies used as an adult. With control for measurement error, more than $50 \%$ of the association between disciplinary history and parenting responses could be attributed to the mediational effects of attitudes. Hence, attitudinal 
sanctioning of violence as a result of victimization may be an important means by which victims are at increased risk for abuse perpetration.

These findings suggest that there may be value in a targeted, early-intervention approach as a means to reduce abuse perpetration. In fact, in recent years, early intervention with preparent (during the prenatal period) and first-time, new parents has increasingly been viewed as critical to prevention efforts (see Donnelly, 1997; U.S. Advisory Board on Child Abuse and Neglect, 1991). When limited financial resources require a focus on smaller, high risk populations, preparents with punitive childhood histories would appear to comprise an appropriate target group for intervention (Kaplan, Pelcovitz, \& Labruna, 1999). The results of this study suggest that an important component of multifaceted intervention approach (e.g., Olds \& Kitzman, 1993) might be the exploration and modification of maladaptive beliefs regarding what constitutes appropriate and effective discipline. Such prevention efforts might focus, for example, on education regarding child development and the limitations of physical disciplinary approaches. Education and support in the mastery of more appropriate and effective alternative disciplinary strategies is probably also critical for pervasive and enduring attitudinal change to occur (see Millar \& Millar, 1996).

This model of the association between disciplinary history, attitudes, and parenting responses should be viewed as a starting point for evaluation, expansion, and elaboration via future research. This study relied on self-reports, and although reactivity effects were probably reduced by the emphasis on anonymity of responding, participants may have underreported socially undesirable attitudes or behaviors, leading to an underrepresentation of the magnitude of association between the constructs of interest. In addition, biases or inaccuracies in the assessment of disciplinary histories may have been introduced by the retrospective nature of the reporting. The fact that the data were collected in group sessions raises the possibility that participants may have been influenced by others in the session; however, these effects may have been reduced by the fact that participants were seated some distance apart and envelopes were used to protect the privacy of completed materials. Finally, because constructs of interest were assessed based on information from a single source, the association between the constructs may be somewhat inflated by method variance (Watson \& Clark, 1984). Although SEM provides a useful statistical tool for exploring potential causal relations, this study was correlational and cross-sectional in design. Further testing of this model using prospective and experimental approaches and control comparisons is warranted.

Given the significant role that nonattitudinal factors likely play in mediating risk for punitive parenting, elaboration of this model to isolate, validate, and quantify the impact of such mediating factors would also be theoretically and practically beneficial. Mediators that might be added to the model abound in the theoretical literature (see Gershoff, 2002, for a recent review) and have included abusive parents' failure to model constructive conflict resolution strategies (e.g., Trickett \& Kuczynski, 1986), problematic social information processing patterns (e.g., Dodge, Bates, \& Pettit, 1990), self control deficits (Reid, Taplin, \& Lorber, 1981), and social learning of aggressive antisocial behavior (e.g., Herzeberger, 1996). The fact that the final model accounted for only $20 \%$ of the variance in parenting responses is consistent with the fact that a punitive childhood disciplinary history appears to contribute to abuse perpetration for only a small percentage of abusers. Factors unrelated to disciplinary history, such as child temperament, parent personality and cognitive style, and characteristics of both the family system and the larger social context (see Belsky, 1993, for a review) must also be considered to fully understand parental disciplinary responding.

One potential limitation of the present study was its analogue design. A primary concern regarding analogue studies is that they may have limited generalizability outside the laboratory. In the present study, disciplinary responding was assessed by having participants view slides and indicate their reaction to the depicted child's behavior. This approach does not capture the truly dynamic and interactive nature of disciplinary exchanges, and although the slides are engaging enough to evoke a range of disciplinary responses, the stimuli may not evoke the same range of emotions that characterize more naturalistic disciplinary contexts. Hence, the study approximates but does not fully represent the kind of data that might be obtained via more naturalistic observation (see DeGarmo, Reid, \& Knutson, in press).

In spite of their limitations, analogue approaches have proven useful for decades as a means of advancing psychological theory (e.g., the effects of selfdisclosure in counseling, the nature of fears and phobias, the effects of behavior modification) and providing for initial hypothesis testing under conditions that allow for more rigorous methodological control than might be available in clinical and community samples (Borkovec \& Rachman, 1979; Kazdin \& Rogers, 1978; Mook, 1983; Stone, 1984; Stopa \& Clark, 2001; Thase \& Page, 1977). In fact, defenders of analogue research 
have argued that virtually all research should be considered analogue in the sense that it provides an imperfect representation of the broader situation to which the researcher is trying to generalize (Kazdin, 1978; Kazdin \& Rogers, 1978).

The use of an analogue design in the present study allowed for very high participation and completion rates $(0 \%$ drop out) and a large final sample size $(n=$ 459). Furthermore, because participants were able to participate in the present study completely anonymously under purely nonthreatening conditions (e.g., no observer, no risk of detection of abuse and related consequences), reactivity was presumably reduced to yield more candid responding. Given that researchers have limited ability to observe parental discipline and the types of events that occasion discipline and abuse, analogue research is likely to continue to play a useful role in abuse research, providing the means and methodological rigor to support the development and initial testing of theories that may then be cross validated using more naturalistic designs.

The sample used in the present study consisted primarily of unmarried, Caucasian individuals between the ages of 18 and 20. This sample did not include a significant representation of minorities, persons from large, urban areas, or members of the lowest socioeconomic strata. Furthermore, although participants were primarily first generation college students and were only in their first or second semester of university studies, they were likely somewhat more educated than preparents in the general population. To the extent that more severely abused individuals may be less likely to pursue higher education, such individuals were probably underrepresented in the sample. It should be noted that the punishment histories of this sample were not benign, however. Using the threshold established in previous research (Berger et al., 1988), $12 \%$ of the respondents in this sample had histories of severely punitive punishment. Although further research is warranted to determine to what extent this model generalizes to less-educated preparents from other ethnic backgrounds and lower socioeconomic strata, this sample was representative of a very large, preparent population of students at regional, Midwestern universities. Given that parents who are adolescents or young adults are at increased risk to perpetrate abuse (Wekerle \& Wolfe, 1993) and have been a focus of primary prevention in the past (e.g., Lewko, Carriere, Whissell, \& Radford, 1986; Wolfe et al., 1997), this captive audience may be an important target for future prevention efforts.

\section{REFERENCES}

Arbuckle, J. L. (1996). Full information estimation in the presence of incomplete data. In G. A. Marcoulides \& R. E. Schumacker (Eds.), Advanced structural equation modeling: Issues and techniques (pp. 243-277). Mahwah, NJ: Lawrence Erlbaum.

Arbuckle, J. L., \& Wothke, W. (1999). Amos 4.0 [Computer software]. Chicago: Smallwaters.

Ashton, V. (2001). The relationship between attitudes toward corporal punishment and the perception and reporting of child maltreatment. Child Abuse \& Neglect, 25, 389-399.

Azar, S. T., Robinson, D. R., Hekimian, E., \& Twentyman, C. T. (1984). Unrealistic expectations and problem solving ability in maltreating and comparison mothers. Journal of Consulting and Clinical Psychology, 52, 687-691.

Azar, S. T., \& Wolfe, D. A. (1998). Child physical abuse and neglect. In E. J. Mash \& R. A. Barkley (Eds.), Treatment of childhood disorders (2nd ed., pp. 501-544). New York: Guilford.

Baron, R. M., \& Kenny, D. A. (1986). The moderator-mediator variable distinction in social psychological research: Conceptual, strategic and statistical consideration. Journal of Personality and Social Psychology, 51, 1173-1182.

Bavolek, S. J. (1989). Assessing and treatment high-risk parenting attitudes. Early Child Development and Care, 42, 99-112.

Belsky, J. (1993). Etiology of child maltreatment: A developmentalecological analysis. Psychological Bulletin, 114, 413-434.

Berger, A. M., Knutson, J. F., Mehm, J. G., \& Perkins, K. A. (1988). The self-report of punitive childhood experiences of young adults and adolescents. Child Abuse E Neglect, 12, 251-262.

Bogaard, H. (1976). Relationships between aggressive behavior in children and parent perception of child behavior. Unpublished doctoral dissertation, University of Oregon.

Borkovec, T., \& Rachman, S. (1979). The utility of analogue research. Behavior Research and Therapy, 17, 253-261.

Bower, M., \& Knutson, J. F. (1996). Attitudes toward physical discipline as a function of disciplinary history and self-labeling as physically abused. Child Abuse EO Neglect, 20, 689-699.

Bower-Russa, M., Knutson, J. F., \& Winebarger, A. (2001). Disciplinary history, adult disciplinary attitudes, and risk for abusive parenting. Journal of Community Psychology, 29, 219-240.

Buntain-Ricklefs, J. J., Kemper, K. J., Bell, M., \& Babonis, T. (1994). Punishments: What predicts adult approval. Child Abuse $\mathcal{E}$ Neglect, 18, 945-955.

Crouch, J. L., \& Behl, L. E. (2001). Relationships among parental beliefs in corporal punishment, reported, stress, and physical child abuse potential. Child Abuse \& Neglect, 25, 413-419.

Daro, D., \& Gelles, R. J. (1992). Public attitudes and behaviors with respect to child abuse prevention. Journal of Interpersonal Violence, 7, 517-531.

Deater-Deckard, K., Pettit, G. S., Lansford, J. E., Dodge, K. A., \& Bates, J. E. (2003). The development of attitudes about physical punishment: An 8-year longitudinal study. Journal of Family Psychology, 17, 351-360.

DeGarmo, D. S., Reid, J. B., \& Knutson, J. F. (in press). Integrating direct observations and laboratory analog measures in research definitions of child maltreatment. In M. Feerick, J. F. Knutson, P. Trickett, \& S. Flanzer, (Eds.), Defining and classifying child abuse and neglect for research purposes. Baltimore, MD: Brookes.

Dodge, K. A., Bates, J. E., \& Pettit, G. S. (1990). Mechanisms in the cycle of violence. Science, 250, 1678-1683.

Donnelly, A. C. (1997). An overview of prevention of physical abuse and neglect. In M. E. Helfer \& R. S. Kempe (Eds.), The battered child (5th ed., pp. 579-593). Chicago: University Of Chicago Press.

Egeland, B., Jacobvitz, D., \& Sroufe, L. A. (1988). Breaking the cycle of abuse. Child Development, 59, 1080-1088.

Ertem, I. O., Leventhal, J. M., \& Dobbs, S. (2000). Intergenerational continuity of child physical abuse: How good is the evidence? Lancet, 356, 814-819.

Flynn, C. P. (1998). To spank or not to spank: The effect of situation and age of child on support for corporal punishment. Journal of Family Violence, 13, 21-37. 
Gelles, R. J. (1973). Child abuse as psychopathology: A sociological critique and reformulation. American Journal of Orthopsychiatry, $43,611-621$

Gershoff, E. T. (2002). Corporal punishment by parents and associated child behaviors and experiences: A meta-analytic and theoretical review. Psychological Bulletin, 128, 539-579.

Gil, D. G. (1970). Violence against children. Cambridge, MA: Harvard University Press.

Gracia, E. (1995). Visible but unreported: A case for the "not serious enough" cases of child maltreatment. Child Abuse E Neglect, 19, 1083-1093.

Graziano, A. M. (1994). Why we should study subabusive violence against children. Journal of Interpersonal Violence, 9, 412-419.

Graziano A. M., \& Namaste, K. A. (1990). Parental use of physical force in child discipline: A survey of 679 college students. Journal of Interpersonal Violence, 5, 449-463.

Herrenkohl, R. C., Herrenkohl, E. C., \& Egolf, B. P. (1983). Circumstances surrounding the occurrence of child maltreatment. Journal of Consulting and Clinical Psychology, 51, 424-431.

Herzberger, S. D. (1983). Social cognition and the transmission of abuse. In D. Finkelhor, R. J. Gelles, G. T. Hotaling, \& M. A. Straus (Eds.), The dark side of families: Current family violence research (pp. 317-329). Beverly Hills, CA: Sage.

Herzberger, S. D. (1996). Violence within the family. Boulder, Colorado: Westview.

Herzeberger, S. D., \& Tennen, H. (1985). The effect of selfrelevance on judgements of moderate and severe disciplinary encounters. Marriage and the Family, 47, 311-318.

Holmbeck, G. N. (1997). Toward terminological, conceptual, and statistical clarity in the study of mediators and moderators: Examples from the child-clinical and pediatric psychology literatures. Journal of Consulting and Clinical Psychology, 65, 599-610.

Jackson, S., Thompson, R. A., Christiansen, E. H., Colman, R. A., Wyatt, J. Buckendahl, et al. (1999). Predicting abuse-prone parental attitudes and discipline practices in a nationally representative sample. Child Abuse E् Neglect, 23, 15-29.

Kaplan, S. J., Pelcovitz, D., \& Labruna, V. (1999). Child and adolescent abuse and neglect research: A review of the past 10 years. Part I: Physical and emotional abuse and neglect. Journal of the American Academy of Child and Adolescent Psychiatry, 38, 1214-1222.

Kaufman, J., \& Zigler, E. (1989). The intergenerational transmission of child abuse. In D. Cicchetti \& V. Carlson (Eds.), Child maltreatment: Theory and research on the causes and consequences of child abuse and neglect (pp. 129-150). New York: Cambridge.

Kazdin, A. E. (1978). Evaluating the generality of findings in analogue therapy research. Journal of Consulting and Clinical Psychology, 46, 673-686.

Kazdin, A. E., \& Rogers, T. (1978). On paradigms and recycled ideologies: Analogue research revisited. Cognitive Therapy and Research, 2, 105-117.

Kelder, L. R., McNamara, J. R., Carlson, B., \& Lynn, S. J. (1991). Perceptions of physical punishment: The relation to childhood and adolescent experiences. Journal of Interpersonal Violence, 6, 432445 .

Knutson, J. F., \& Bower, M. E. (1994). Physically abusive parenting as an escalated aggressive response. In M. Potegal \& J. F. Knutson (Eds.), The dynamics of aggression: Biological and social processes in dyads and groups (pp. 195-225). Hillsdale, NJ: Lawrence Erlbaum.

Knutson, J. F., Johnson, C. R., \& Sullivan, P. M. (2004). Disciplinary choices of mothers of deaf children and mothers of normally hearing children. Child Abuse E Neglect, 28, 925-937.

Knutson, J. F., \& Mehm, J. G. (1988). Transgenerational patterns of coercion in families and intimate relationships. In G. W. Russell (Ed.), Violence in intimate relationships (pp. 67-90). New York: Publishers Marketing Association.

Kraus, S. J. (1995). Attitudes and the prediction of behavior: A metaanalysis of the empirical literature. Personality and Social Psychology Bulletin, 21, 58-75.

Larrance, D. T., \& Twentyman, C. T. (1983). Maternal attributions and child abuse. Journal of Abnormal Psychology, 92, 449-457.
Lewko, J., Carriere, R., Whissell, C., \& Radford, J. (1986). Final report of the study investigating the long term effectiveness of the parenting for teens and child project. Sudbury, Ontario, Canada: Laurentian University, Center for Research in Human Development.

MacKinnon, D. P., \& Dwyer, J. H. (1993). Estimating mediated effects in prevention studies. Evaluation Review, 17, 144-158.

Margolin, L., \& Craft, J. L. (1990). Child abuse by adolescent caregivers. Child Abuse E Neglect, 14, 365-373.

Masten, A. A., Best, K. M., \& Garmezy, N. (1990). Resilience and development: Contributions from the study of children who overcome adversity. Development and Psychopathology, 2, 425-444.

Millar, M. G., \& Millar, K. U. (1996). The effects of direct and indirect experience on affective and cognitive responses and the attitude-behavior relation. Journal of Experimental Social Psychology, 32, 561-579.

Miller, K. S., \& Knutson, J. F. (1997). Reports of severe physical punishment and exposure to animal cruelty by inmates convicted of felonies and by university students. Child Abuse E Neglect, 21, 5982.

Mook, D. G. (1983). In defense of external invalidity. American Psychologist, 38, 379-387.

Newcomb, M. D. (1990). What structural equation modeling can tell us about social support. In B. R. Sarason, I. G. Sarason, \& G. R. Pierce (Eds.), Social support: An interactional view (pp. 26-63). Oxford, England: John Wiley \& Sons.

Olds, D. L., \& Kitzman, H. (1993). Review of research on home visiting for pregnant women and parents of young children. Future of Children, 3(3), 53-92.

Portwood, S. (1998). The impact of individuals' characteristics and experiences on their definitions of child maltreatment. Child Abuse E् Neglect, 22, 437-452.

Prescott, A., Bank, L., Reid, J. B., Knutson, J. F., Burraston, B. O., \& Eddy, J. M. (2000). The veridicality of retrospective reports of punitive childhood experiences. Child Abuse E Neglect, 24, 411423.

Rausch, K., \& Knutson, J. F. (1991). The self-report of personal punitive childhood experiences and those of siblings. Child Abuse E Neglect, 15, 29-36.

Reid, J. B. (1985). Social interactional patterns in families of abused and nonabused children. In C. Zahn-Waxler, M. Cummings, \& M. Radke-Yarrow (Eds.), Social and biological origins of altruism and aggression (pp. 33-45). New York: Cambridge University Press.

Reid, J. B., Taplin, P. S., \& Lorber, R. (1981). A social interactional approach to the treatment of abusive families. In R. Stuart (Ed.), Violent behavior: Social learning approaches to prediction, management, and treatment (pp. 83-101). New York: Brunner/Mazel.

Rodriguez, C. M., \& Price, B. L. (2004). Attributions and discipline history as predictors of child abuse potential and future discipline practices. Child Abuse E Neglect, 28, 845-861.

Rodriguez, C. M., \& Sutherland, D. (1999). Predictors of parents' physical disciplinary practices. Child Abuse $\mathcal{E}$ Neglect, 23, 651657.

Rutter, M. (1983). Stress, coping, and development: Some issues and some questions. In N. Garmezy \& M. Rutter (Eds.), Stress, coping, and development in children (pp. 1-41). New York: McGrawHill.

Sapp, A. D., \& Carter, D. L. (1978). Child abuse in Texas: A descriptive study of Texas residents' attitudes. Huntsville, TX: Sam Houston State University.

Simons, R. L., Whitbeck, L. B., Conger, R. D., \& Chyi-In, W. (1991). Intergenerational transmission of harsh parenting. Developmental Psychology, 27, 159-171.

Socolar, R. R. S., \& Stein, R. E. K. (1995). Spanking infants and toddlers: Maternal belief and practice. Pediatrics, 95, 105-111.

Steele, B. F., \& Pollack, C. B. (1974). A psychiatric study of parents who abuse infants and small children. In R. E. Helfer \& C. H. Kempe (Eds.), The battered child (2nd ed., pp. 89-133). Chicago: University of Chicago Press.

Stone, G. L. (1984). Comments. Reaction: In defense of the "artificial.” Journal of Counseling Psychology, 31, 108-110. 
Stopa, L., \& Clark, D. M. (2001). Social phobia: Comments on the viability and validity of an analogue research strategy and British norms for the fear of negative evaluation questionnaire. Behavioral and Cognitive Psychotherapy, 29, 423-430.

Straus, M. A. (1980). Stress and physical child abuse. Child Abuse E Neglect, 4, 75-88.

Straus, M. A. (1992, April). Corporal punishment of children and depression and suicide in adulthood. Paper presented at the Society for Life History Research, Philadelphia, PA.

Straus, M. A., Gelles, R. J., \& Steinmetz, S. K. (1980). Behind closed doors: Violence in the American family. New York: Anchor.

Susman, E. J., Trickett, P. K., Iannotti, R. J., Hollenbeck, B. E., \& Zahn-Waxler, C. (1985). Child-rearing patterns in depressed, abusive, and normal mothers. American Journal of Orthopsychiatry, 55, 237-251.

Thase, M., \& Page, R. A. (1977). Modeling of self-disclosure in laboratory and nonlaboratory settings. Journal of Counseling Psychol ogy, 24, 35-40.

Thompson, R. A., Christiansen, E. H., Jackson, S., \& Wyatt, J. M. (1999). Parent attitudes and discipline practices: Profiles and correlates in a nationally representative sample. Child Maltreatment, 4, 316-330.

Trickett, P. K., \& Kuczynski, L. (1986). Children's misbehaviors and parental discipline strategies in abusive and nonabusive families. Developmental Psychology, 22, 115-123.

U.S. Advisory Board on Child Abuse and Neglect. (1991). Creating caring communities: Blue-print for an effective federal policy on child abuse and neglect. Washington, DC: Government Printing Office.

Wahler, R. G., Williams, A. J., \& Cerezo, A. (1990). The compliance and predictability hypotheses: Sequential and correlational analyses of coercive mother-child interactions. Behavioral Assess ment, 12, 391-407.

Watson, D., \& Clark, L. (1984). Negative affectivity: The disposition to experience aversive emotional states. Psychological Bulletin, 96, 465-490.

Wekerle, C., \& Wolfe, D. A. (1993). Prevention of child physical abuse and neglect: Promising new directions. Clinical Psychology Review, 13, 501-540.

Whitmore, E. A. W., Kramer, J. R., \& Knutson, J. F. (1993). The association between punitive childhood experiences and hyperactivity. Child Abuse Eं Neglect, 17, 357-366.
Widom, C. S. (1989). Does violence beget violence? A critical examination of the literature. Psychological Bulletin, 106, 3-28.

Williamson, J., Borduin, C., \& Howe, B. (1991). The ecology of adolescent maltreatment: A multilevel examination of adolescent physical abuse, sexual abuse, and neglect. Journal of Consulting and Clinical Psychology, 59, 449-457.

Wilson, S. R., \& Whipple, E. E. (1995). Communication, discipline, and physical child abuse. In T. J. Socha \& G. H. Stamp (Eds.), Parents, children and communication: Frontiers of theory and research (pp. 299-317). Hillsdale, NJ: Lawrence Erlbaum.

Winebarger, A. A., Leve, L. D., Fagot, B. I., \& May, P. (1993, April). Adult retrospective impressions of parenting behaviors. Paper presented at the annual convention of the Western Psychological Association, Tucson, AZ.

Wolfe, D. A., Wekerle, C., Reitzel-Jaffe, D., Grasley, C., Pittman, A., \& MacEachran, A. (1997). Interrupting the cycle of violence: Empowering youth to promote healthy relationships. In D. A. Wolfe, R. J. McNamara, \& R. D. Peters (Eds.), Child abuse: New directions in prevention and treatment across the lifespan (pp. 102129). Thousand Oaks, CA: Sage.

Worling, J. R. (1995). Adolescent sibling-incest offenders: Differences in family and individual functioning compared to adolescent nonsibling sex offenders. Child Abuse Eं Neglect, 19, 633643.

Zaidi, L. Y., \& Foy, D. W. (1994). Childhood abuse experiences and combat-related PTSD. Journal of Traumatic Stress, 7, 33-41.

Zaidi , L. Y., Knutson, J. F., \& Mehm, J. G. (1989). Transgenerational patterns of abusive parenting: Analog and clinical tests. Aggressive Behavior, 15, 137-152.

Zoline, S. S., \& Jason, L. (1985). Preventive parent education for high school students. Journal of Clinical Child Psychology, 14, 119123.

Mary Bower Russa is an associate professor of psychology at Grand Valley State University. Her interests include child abuse, support and coping, and physical disabilities. She is also a licensed psychologist. 